\title{
Treatment of Fractures of Distal End of Radius Using Ligamentotaxis: A Case Series
}

\author{
S.Tontanahal ${ }^{1}$, T.D.Bhattacharyya ${ }^{2}$, S.Mittal $^{3}$, R.Ailani $^{4}$, A.Gaikwad $^{5}$ \\ Gauhati Medical College, Guwahati,Assam
}

\begin{abstract}
Introduction: Intra/juxta-articular fractures of distal radius are still challenging problem despite the varieties of modalities of treatment options. We report the result of a prospective study of three hundred fifty patients, who were treated by close reduction and simple single bar Uniplaner external fixator.

Methodology: In a prospective controlled study, 350 cases of distal end radius fractures with / without intra-articular extension were treated with uniplanar static type of external fixation using the principle of ligamentotaxis and augmentation by $K$-wires. The age group of the patients is 18 to 70 years, external fixator was applied for duration of 6 to 8 weeks and cases were followed up for an average of 6 to 10 months post operatively.

Results: Assessed as per Demerit point system of Gartland and Werley (modified by Sarmiento 1975) for functional results and criteria for anatomical results by Sarmiento (1975) at the end of 6-8 months of follow up. Excellent anatomical result was seen in around $37 \%$ patients, good results seen in $46 \%$ patients, fair results are seen in around $15 \%$ patients with poor results in around $2 \%$ patients.

Conclusion: Thus we conclude that ligamentotaxis is an excellent method for the management of comminuted intra/juxta articular fractures. It not only obviates the need of ORIF and/or POP cast but also gives better functional results. It is very useful in compound comminuted fractures around joints where other methods are contraindicated.
\end{abstract}

Keywords: Distal radius fractures, ligamentotaxis, functional outcome.

\section{- Introduction}

Fractures of the distal radius continue to be the most common skeletal injuries treated by the orthopedic surgeon. In fact these injuries are the most common fractures of the upper extremity and account for approximately $1 / 6$ th $(16 \%)$ of all fractures seen and treated in emergency rooms ${ }^{[1,2,3]}$. Distal radius fractures disturb the mechanical foundation of the man's most elegant tool, the hand. No other fracture has a greater potential to devastate hand function. The same ligaments, retinaculae, tendons and the periosteum that envelop the fracture which are the surgical barrier for open reduction of the fracture fragments, help to achieve reduction of the fracture by ligamentotaxis ${ }^{[4]}$.

Many fractures of the distal aspect of the radius are relatively uncomplicated and are effectively treated by closed reduction and immobilization in cast. However unstable / intra-articular fractures can jeopardize the integrity of the articular congruence and /or kinematics of these articulations ${ }^{[5]}$. Several factors have been associated with the instability ${ }^{[6]}$, these include the following:

- The initial displacement of the fracture .The greater the degree of the initial displacement is (especially radial shortening), the more energy was imparted to the fracture, resulting in a higher likelihood that closed treatment will be unsuccessful.

- The age of the patient. Fractures in elderly patients with osteopenic bones tend to displace particularly late.

- The extent of metaphyseal comminution (the metaphyseal defect) especially when comminution extends into the palmar buttress, collapse occurs even in the face of cast immobilisation.

- The amount of intra-articular comminution and steps.

- Finally, displacement after closed treatment is a predictor of instability, and repeat manipulation is unlikely to result in a successful radiographic outcome

External fixation and distraction is one method to restore radial length and maintain reduction, thus improving radiological and functional outcomes ${ }^{[7,8]}$. External fixation represents the first line of treatment for unstable distal radius fractures ${ }^{[9]}$.

\section{Aims and Objectives}

The main aim of this dissertation is to evaluate the results obtained by treatment of distal end radius fractures by external fixation in terms of: 
- Duration of immobilization in external fixation.

- Restoration of anatomy of distal end radius (radial length, palmar tilt and radial angulation).

- Effectiveness in allowing early motion of digits and rehabilitation.

- Prevention of deformity and disability due to malunion.

- Evaluation of treatment related complications.

\section{- Materials and Methods}

A prospective study was carried out for a total of 350 cases of distal radial fractures aged between 18yrs-70yrs attending the OPD and Emergency department of Orthopaedics, Gauhati Medical College \& Hospital who meet the inclusion and exclusion criteria outlined below. All the cases were followed up for a minimum period of six months.

\section{Inclusion Criteria:}

- Only those patients who give consent will be included in the study.

- All distal radial fractures in patients aged 18-70yrs.

- Competent neurological and vascular status of the affected limb.

- No associated fractures in same limb.

- Patients with polytrauma in which upper extremity treatment may allow early patient mobilization using crutches or walkers.

\section{Exclusion Criteria:}

- Patients who do not give consent.

- Patients aged $<18 \mathrm{yrs}$ and $>70 \mathrm{yrs}$

- Inability to take part in post-operative rehabilitation.

- Medical contraindications to surgery/anaesthesia.

- Patients with pathological fractures.

- Fractures with history of trauma $>10$ days.

After appropriate radiological and pre-operative investigations the individual was posted for surgery. Closed manipulation was done and AO type of uniplanar static type of external fixator was applied using the principle of ligamentotaxis. $\mathrm{K}$ wire augmentation was done if the need arose.

Patients were discharged after the $3^{\text {rd }}$ to $10^{\text {th }}$ post-operative day depending on the condition and external wound healing and advised active exercises. Patient followed up at 3 weeks for pain, swelling, pin tract infection, pin loosening and stiffness of fingers, elbow or shoulder. On follow up at $6^{\text {th }}$ week, the fracture union was assessed clinically by absence of tenderness and radiologically by bridging callus formation. Then the external fixator and ' $\mathrm{K}$ ' wires were removed under general anaesthesia or on out-patient basis in the minor operation theatre. The patients were advised not to lift heavy weights for further 4 to 6 weeks.

Further follow ups were done on $6^{\text {th }}, 9^{\text {th }}$ and $12^{\text {th }}$ weeks after the operative procedure. Patients were assessed subjectively for pain at the fracture site, clinically for tenderness, loosening of the pins and any signs of infection. Pronation and supination of the forearm and active movement of the elbow and shoulder were advised throughout the period of healing. After the 6th week, physiotherapy was started, which included flexion-extension, adduction - abduction and pronation - supination exercises. The range of wrist movements was recorded and any deformity was assessed

Check X-rays were taken at 6 weeks, 9 weeks and at 3 months, to assess consolidation or collapse at the fracture site and to note any displacement. The fracture was considered united when clinically there was no tenderness, subjective complaints, and radiologically when the fracture line was not visible.

\section{- Observation and Results}

All the patients were followed up for a minimum period of six months and maximum follow up was for 15 months. Follow up was carried out at 3, 6, 9, 12 weeks and then every 3 months. Full assessment was done at the end of 3 months from the date of operation.

The observations of our studies were as follows:

\section{- Fracture Union}

The criteria of Anderson et al (1975) were taken into account to assess the union of the fracture. A fracture was defined as healed when there was obliteration of fracture line and evidence of bridging trabeculae. Accordingly, all of the fractures in the study united without the need for a second procedure, within 3 months. Thus the union rate was $100 \%$, with no delayed or non-unions in the study. The average time taken for union was 7.65 weeks.

\section{- Range of Motion}


- Palmar Flexion: The mean range of palmar flexion in the study was found to be 66.75 degrees.

- Dorsiflexion: The mean range of dorsiflexion in the study was found to be 67.25 degrees.

- Radial Deviation: The mean range of radial deviation in the study was 13.25 degrees.

- Ulnar Deviation: The mean range of ulnar deviation in the study was 19 degrees.

- Supination: The mean range of supination in the study was found to be 72.75 degrees.

- Pronation: The mean range of pronation in the study found to be 67.25 degrees.

- Radiological Assessment

- Radial Inclination: The mean radial inclination in the study was found to be 19 degrees.

- Volar Inclination: The mean volar inclination in the study was found to be 6.6 degrees.

- Ulnar Variance: The mean ulnar variance in the study was found to be $-0.8 \mathrm{~mm}$.

- Evaluation of Results

\section{- Gartland and Werley Demerit Score System}

The functional results were evaluated by using demerit score system of Gartland and Werley ${ }^{[10]}$ (modified by Sarmiento et al ${ }^{[11]}$ ) based on objective and subjective criteria, residual deformity and complications (score ranging from $0-52$ ).

The average G \& W score was 7.95 with a range from 1 to 24 .

After calculating the G \& W score for each of the patients, their final outcome was categorized into one of four groups as per the score. Satisfactory results were defined for those having "excellent" or "good" result.

\begin{tabular}{|l|l|l|l|l|}
\hline & EXCELLENT & GOOD & FAIR & POOR \\
\hline NO OF CASES & 130 & 161 & 53 & 6 \\
\hline PERCENTAGE & 37.14 & 46 & 15.14 & 1.72 \\
\hline
\end{tabular}

\section{- Stewart Anatomical Score System (Radiographic Evaluation)}

Radiological evaluation is done by Stewart score system using dorsal angle, loss of radial length and loss of radial angle. The outcome of the patients were categorized into four groups excellent (0), good (1-3), fair (4-6) and poor $(>7)$.

\section{- Complications}

\begin{tabular}{|l|l|l|l|l|}
\hline & EXCELLENT & GOOD & FAIR & POOR \\
\hline NO OF CASES & 53 & 245 & 28 & 24 \\
\hline PERCENTAGE & 15.14 & 70 & 8 & 6.86 \\
\hline
\end{tabular}

All the patients were followed up at regular interval and checked for early and late complications. Following were the complications noted at the end of three month follow up

\begin{tabular}{|l|l|}
\hline Complications & No. of patients \\
\hline Pin site infection & 87 \\
\hline Pin loosening & 10 \\
\hline Tendon rupture & 0 \\
\hline Compression Neuropathy & 0 \\
\hline Nerve injury (SRN) & 0 \\
Sudek's osteodystrophy & 0 \\
\hline Malunion & 0 \\
\hline
\end{tabular}

\section{- Discussion}

The fracture of distal end radius is the most common fracture we treat. Management of fracture distal end of radius is still a challenge for orthopaedic surgeon and pose therapeutic problem in term of reduction of fracture, maintenance of reduction till the fracture unites and mobility of the joint after fracture union. Failure in the management may cause permanent disability ${ }^{[12]}$. But the outcome of these fractures is not uniformly good regardless of treatment instituted. We agree with GREEN that a good functional result usually accompanies a good anatomical reduction ${ }^{[13]}$. The small A.O external fixator provides a simple and reliable means of treating distal end radial fractures especially unstable intraarticular fractures employing the concept of ligamentotaxis that was proposed by Vidal et al ${ }^{[14]}$. The efficacy of ligamentotaxis in neutralizing detrimental compression forces, which are likely to cause displacement of unstable fracture with radial shortening, is a significant and increasingly appealing advance in the management of distal radius fracture ${ }^{[6]}$.

\section{- Union of Fractures}

In our study all fractures are united within three months and union rate was $100 \%$. The time taken for radiological union ranged from 6 to 12 weeks, with a mean of 7.65 weeks. Our finding in this respect is consistent with that of Agarwal et $\mathrm{al}^{[15]}$, Dai et al ${ }^{[16]}$ and Jalil et al ${ }^{[17]}$. 
The following table compares the time for radiological union in our study groups with that of other studies.

\begin{tabular}{|l|l|l|l|}
\hline Study (Year) & Operation & Mean Union time(Weeks) & Range(week) \\
\hline $\begin{array}{l}\text { 1. Agarwal et al }{ }^{[15]} \\
2004\end{array}$ & ORIF with T-plate & 8.8 & $7-10$ \\
\hline 2. Dai et al ${ }^{[16]}, 2006$ & PLATING+PINNING & - & $<12$ \\
\hline 3. Jalil et al $^{[17]}, 2010$ & LCP & 7.5 & $6-9$ \\
4. Tang et al & & - \\
\hline 5. Present study 2012 & Anatomical Plate & $12.93 \pm 2.23$ & -- \\
\cline { 2 - 4 } & Locking Plate & $11.76 \pm 2.61$ & $6-12$ \\
\hline
\end{tabular}

\section{- $\quad$ Results And Outcomes}

At the end of three months we evaluated our results for each patient in terms of total G \& W score and graded them accordingly. Overall we obtained "excellent" results in $37.14 \%$; "good" in $46 \%$ cases; "fair" in $15.14 \%$ and "poor" in $1.72 \%$ cases with a mean G \& W score of 6.35 . Therefore a satisfactory result was obtained in $83.14 \%$ cases

Patients, who obtained excellent results, had no residual deformities or pain. Range of motion was within the normal functional range. They had no arthritic changes or other complications. Radial length, volar tilt and articular step-off were within acceptable limits. They were co-operative to physiotherapy. Patients with good results had minimal residual deformities, pain and slight limitation. Rest of their findings was within acceptable parameters.

In 1961, Dowling and Sawyer evaluated results of percutaneus pinning fixation in 51 patients with $84 \%$ excellent to good results ${ }^{[19]}$. In 1979, Cooney et al published results of 60 patients treated with R.A Frame with $87 \%$ excellent to good results ${ }^{[20]}$. In 1984, D'Anca et al evaluated results of Hoffman fixation in 54 patients with $94 \%$ excellent to good results ${ }^{[21]}$. In 1984, Schuind et al evaluated results of Hoffman fixation in 63 patients with $94 \%$ excellent to good results ${ }^{[22]}$. In 1985 , Vaughan et al published results of 52 patients treated with R.A Frame with $94 \%$ excellent to good results ${ }^{[23]}$. In 1987, Jenkins et al published results of 72 patients treated with A O Fixator with $93 \%$ excellent to good results ${ }^{[24]}$. In 1989, Howard evaluated results of Hoffman fixation in 50 patients with $96 \%$ excellent to good results. In 1991, Jakim et al evaluated results of Hoffman fixation in 132 patients with $83 \%$ excellent to good results ${ }^{[25]}$. In 1991, Edwards published results of A O fixation in 30 patients with $96 \%$ excellent to good results ${ }^{[26]}$. In 2000 Kapoor H Aggarwal concluded from their studies in 90 cases of unstable distal radius fractures that results were good or excellent in $80 \%$ of external fixator. In April 2001, Markowitz AD published a paper on five pin external fixator and early mobilization. They emphasized to use on dorsal pin (additional) incorporated in external fixator to correct dorsal tilt found in many fractures of distal end radius. Additional pins would help to reduce those fragments that would not improve with traction alone, thus unnecessary excessive traction is avoided ${ }^{[27]}$. In 2010, Aktekin et al. found that wrist extension, ulnar deviation, palmar tilt and radial height were better in those treated with external fixation ${ }^{[28]}$. In 2012 , Wei et al. reported good results with external fixation when satisfactory reduction is obtained ${ }^{[29]}$. In 2013 , Rajeev shukla et al concluded from their studies in 72 cases of intraarticular distal radius fractures that Joshi"s External Stabilizing System is a cost effective technique and a good option in displaced distal end radial fractures ${ }^{[30]}$. In 2014, Deepak CD, Gopalakrishna G, Ravoof A et. al. assessed the results of 20 patients of unstable distal radius fractures with / without intra-articular extension and concluded that external fixation and ligamentotaxis provides better functional and anatomical results in comminuted intra-articular and unstable extra-articular wrist injuries $^{[31]}$. In 2015, reports from Rakesh K Yalavarthi, Amar Vishal et al yielded similar findings on treating 33 cases of fractures of distal radius with external fixator ${ }^{[32]}$.

\begin{tabular}{|c|c|c|c|c|c|}
\hline \multirow[t]{2}{*}{ S NO. } & \multirow[t]{2}{*}{ Name of Series } & \multirow[t]{2}{*}{ Modality of Treatment } & \multirow[t]{2}{*}{ No of Cases } & \multicolumn{2}{|c|}{ Results (Functional) } \\
\hline & & & & $E \& G$ & $\mathrm{~F} \& \mathrm{P}$ \\
\hline 1. & Rakesh Yalavarthi et al $(2015)^{[32]}$ & A.O & 33 & 88 & 12 \\
\hline 2. & Deepak CD (2014) $)^{[31]}$ & A.O & 20 & 75 & 9 \\
\hline 3. & Rajeev Shukla (2013) ${ }^{[30]}$ & JESS & 72 & 77.8 & 22.2 \\
\hline 4. & GS Edwards (1991) ${ }^{[26]}$ & A.O & 30 & 96 & 4 \\
\hline 5. & I. Jakim et al (1991) ${ }^{[25]}$ & Hoffmann & 132 & 83 & 17 \\
\hline 6. & Howard 1989 & Hoffmann & 50 & 96 & 4 \\
\hline 7. & Jenkins et al (1987) ${ }^{[24]}$ & A.O & 72 & 93 & 7 \\
\hline 8. & Vaughan et al (1985) ${ }^{[23]}$ & R.A frame & 52 & 94 & 6 \\
\hline 9. & Schuind et al (1984) ${ }^{\lfloor 22\rfloor}$ & Hoffmann & 63 & 94 & 6 \\
\hline 10. & D"Anca et al (1984) ${ }^{[21]}$ & Hoffmann & 54 & 94 & 6 \\
\hline 11. & Cooney et al (1979) ${ }^{[20]}$ & R.A frame & 60 & 87 & 13 \\
\hline 12. & Cole and Obletz (1966) ${ }^{[10]}$ & Pins \& plaster & 33 & 94 & 6 \\
\hline 13. & Dowling and sawyer $(1961)^{[19]}$ & Perc pinning & 51 & 84 & 16 \\
\hline 14. & Current study (2015) & A.O & 350 & 83 & 17 \\
\hline
\end{tabular}




\section{- Conclusion}

A small Uniplaner external fixator is a simple and reliable means of treating unstable severely comminuted intraarticular fracture of the distal radius with the proved and accepted concept of ligamentotaxis. It is a simple apparatus for application and can produce excellent to good results. The final functional result of treatment of distal radius fractures not only depends on the anatomical restoration of the articular surface but also on the associated soft tissue injuries and articular damage.

Finally the conclusions that can be drawn from this study are:

- The superior mechanical efficiency of the fixator.

- It is a simple device and easy and safe to use even under regional anesthesia.

- The shorter period of surgery and minimal exposure.

- Can be performed in emergency with minimum instrumentation and expertise.

Finally we would like to conclude that External fixator is an easy, cost effective, reliable and most suitable treatment in treating intraarticular and unstable extraarticular distal end radial fractures by the "Principle of ligamentotaxis".

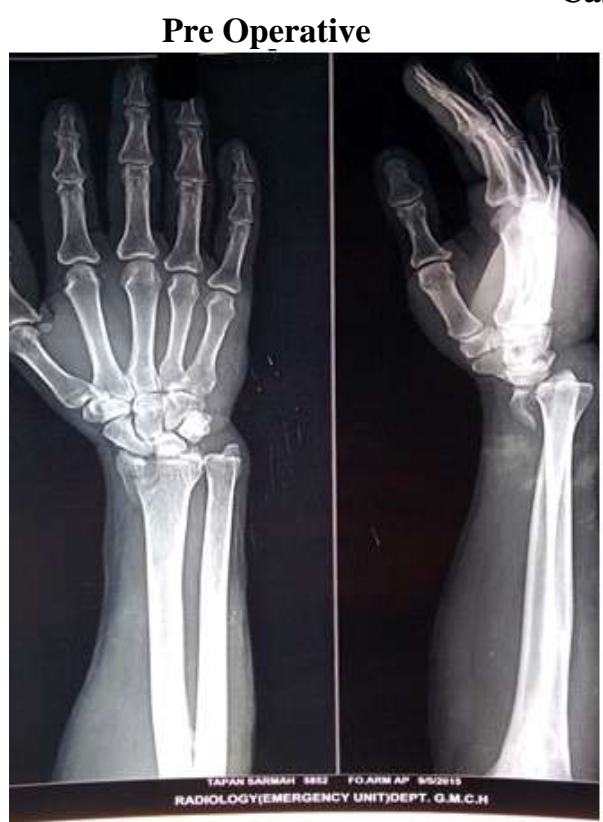

\section{Case Radiographs}
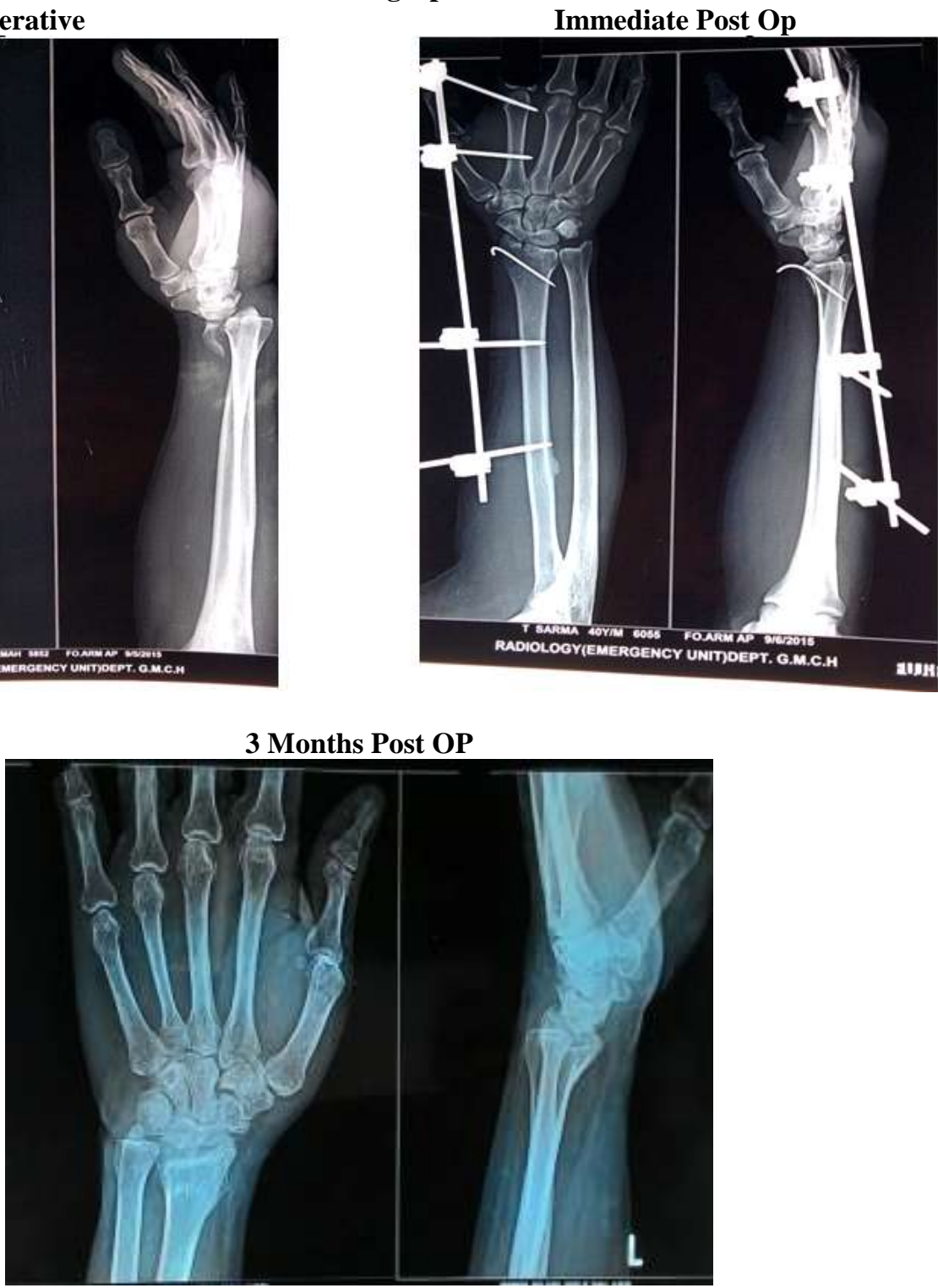


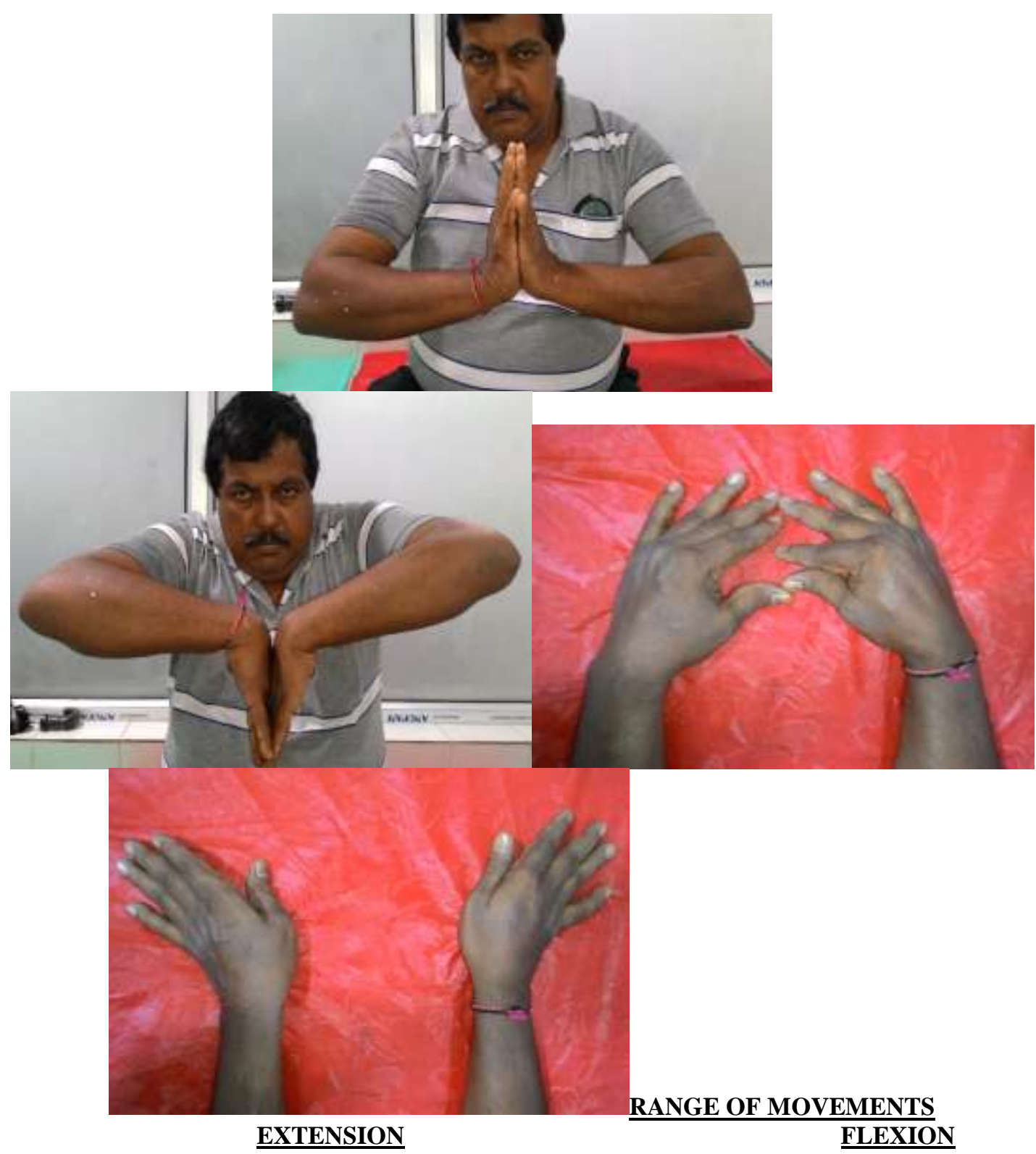

RADIAL DEVIATION

ULNAR DEVIATION

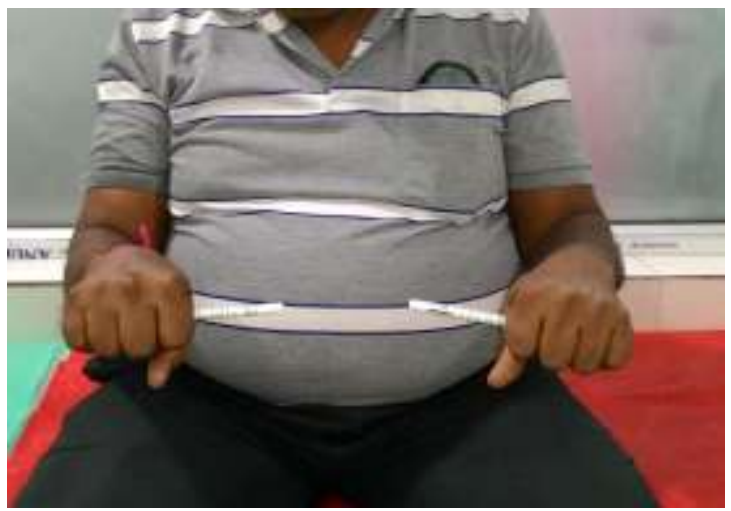

Supination

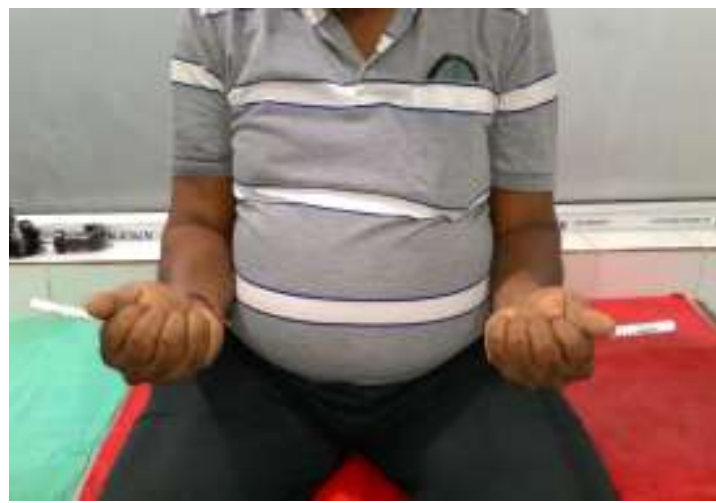

Pronation 


\section{References}

- $\quad$ Ark J, Jupiter JB. The rationale for precise management of distal radius fractures. Orthop Clin North Am. 1993 April; 24(2): 205-210

- $\quad$ Nagi ON, Dhillon MS, Aggarwal S, Deogaonkar KJ. External fixators for intra-articular distal radius fractures. Indian Journal of Orthopaedics. 2004;38: 19-22.

- Jupiter JB. Current concepts review - Fractures of the distal end of the radius. J Bone Joint Surg (Am). 1991; 73-A: 461-469.

- Agee JM. External fixation: Technical advances based upon multiplanar Ligamentotaxis. Othop Clin North Am. 1993; 24 (2): 265-274.

- $\quad$ Simic PM., Weiland AJ. Fractures of the distal aspect of the Radius: Changes in Treatment Over the past two decades. J Bone Joint Surg (Am).2003; 85-A: 552-564.

- $\quad$ Bucholz RW, Heckman JD, Charles M. Rockwood \& Green's Fractures in Adults. 6th ed.Lippincott Williams \& Wilkins, 2006.

- Artroshi I, Brogren E, Larsson GU, Kloow J, Hofer M, Berggren A M.Wrist bridging versus non bridging external fixation for displaced distal radius fracture :A randomized assessor-blind clinical trial of 38 patients followed for 1 year. Acta Orthop 2006; 77 : 445-53.

- $\quad$ Kreder HJ, Agel J, McKee MD, Schemitsch EH, Stephen D, Hanel DP. A randomized controlled trial of distal radius fracture with meta physeal displacement but without joint incongruity: closed reduction and casting versus closed reduction, spanning external fixation and optional percutaneous K wire. J Orthop Trauma 2006; 20: 115-21.

- Harley BJ, Scharfenberger A, Beaupre LA, Jomha N, Weber DW. Augmented external fixation versus percutaneous pinning and casting for unstable fracture of the distal radius -a prospective randomized trial. J Hand Surg Am 2004; 29 : 815-24.

- $\quad$ Gartland J, Werley C. Evaluation of healed Colles' fractures. J Bone Joint Surg 1951; 33(4):895-907.

- $\quad$ Sarmiento A, Pratt GW, Berry NC, Sinclair WF. Colles' fracture: functional bracing in supination. J Bone Joint Surg Am. 1975; 57:311-317.

- Boparai RPS, Boparai RS, Kapilar, Pandher DS. Role of ligamentotaxis in management of comminuted intra/juxta articular fractures. Indian Journal of Orthopaedics 2006; 40, (3):185-7.

- $\quad$ Green D P. Pins and plaster treatment of comminuted fracture of the distal end of the radius. J Bone Joint Surg Am. 1975; 57-A: 304-310.

- Vidal J. Buscayret, Fischbach: Une methode originale dans le traitement des fractures comminutives de du radius „Le taxis ligamentaire" Acta Orthop. Belgica 43; 781-789, 1977.

- $\quad$ Agarwal AK, Nagi ON. Open reduction and internal fixation of volar Barton's fracture; a prospective study. Journal of Orthopaedic Surgery 2004;12(2):230-234.

- Dai MH, Wu CC, Liu HT, et al. Treatment of volar Barton's fractures: comparison between two common surgical techniques. Chang Gung Med J. 2006; 29(4):388-394.

- Jalil SA, Mughal RA, Haque SN, Shah RA. Treatment outcome of Volar Barton fracture fixed with locking compression plates. Pak J Surg 2010; 26(4):265-268.

- $\quad$ Tang Z, Yang H, Chen K, et al. Therapeutic Effects of Volar Anatomical Plates Versus Locking Plates for Volar Barton's Fractures. Orthopedics 2012; 35(8): e1198-e1203.

- $\quad$ Dowling JJ \& Sawyer Blackwell: Comminuted Colles fractures evaluation of method of treatment JBJS 43-A 657-668 July 1961.

- $\quad$ Cooney, W.P., Agee, J.M., Hastings, H.I., Melone, C.P.J., and Rayhack, J.M.: Management of Intraarticular Fractures of the Distal Radius. Contemp Ortho 21:71-104, 1990.

- $\quad$ D"Anca AF, Byron TW, Feinstein PA. External fixator management of unstable Colles fractures Orthopedics 1984; 7:853-9.

- $\quad$ Schuind F, M, Burny F. External fixator for wrist fractures Orthopaedics 1984;7:841-4.

- $\quad$ Vaughan PA etal: Treatment of unstable fractures of distal radius by external fixator, JBJS 67(B) 385, 1985.

- Jenkins N.H Jones D.G Johnson S.R and Mintocout WJ: External fixation for Colles fracture: An anatomical study JBJS 69 B2:207211, 1988 .

- Jakim I, Pieters HS Smeet MBE: External fixation for intraarticular fractures of distal radius JBJS 1991, March: 73(2); $302-306$.

- G S Edwards JBJS Am 1991; 73:1241-1250.

- $\quad$ Markiewitz AD: Five pin external fixator and early range of motion for distal radius fracture, Orth, Clinics of North America 2000 APRIL.

- $\quad$ Aktekin CN, Altay M, Gursoy C, et al: Comparison between external fixation and cast treatment in the management of distal radius fractures in patients aged 65 years and older, J Hand Surg 35:86, 2010.

- Wei DH, Poolman RW, Bhandari M, et al: External fixation versus internal fixation for unstable distal radius fractures: a systematic review and meta-analysis of comparative clinical trials, J Orthop Trauma 26:386, 2012.

- $\quad$ Rajeev Shukla .A multifactorial study of application of Joshi"s External Stabilizing System indisplaced Distal End Radius Fractures.Indian Journal of Basic and Applied Medical Research; December 2013: Vol.-3, Issue-1, P. 165-171.

- Deepak CD, Gopalakrishna G, Ravoof A et. al. Surgical management of distal end radius fractures by ligamentotaxis. Int J Health Sci Res. 2014;4(4):106-110.

- Yalavarthi RK, Vishal A et. al. Outcome of Management of Distal Radius Fractures By Ligamentotaxis. IOSR-JDMS; July 2015: .Volume 14, Issue 7 Ver. II: 33-37. 